\title{
Perspectivas Metodológicas de Ensino no Ciberespaço: O Caso dos Seminários Virtuais no CEAD/UFOP
}

Wellington Tavares - CEPEAD/UFMG e CEAD/UFOP - wellington@ cead.ufop.br Mirian Assumpção e Lima - CEAD/UFOP - mirian@ @ead.ufop.br

Helton Cristian de Paula - CEPEAD/UFMG e CEAD/UFOP - helton@ cead.ufop.br

Resumo: Este estudo apresenta alguns conceitos contemporâneos, tais como ciberespaço e inteligência coletiva, que emergiram das transformações por que passaram as tecnologias da informação e comunicação. Tais transformações possibilitaram a apropriação de novos espaços de interação para os atores envolvidos nos processos de ensino-aprendizagem: alunos, tutores e professores. Para melhor esclarecimento dos conceitos, este estudo objetiva analisar um caso que conta com dois fatos estritamente relacionados: uma pesquisa de expectativas a respeito de uma disciplina e, em decorrência desta, o desenvolvimento de uma diferente metodologia de avaliação virtual. Por fim, elabora-se uma discussão acerca da nova metodologia desenvolvida, além de análises sobre os processos e a avaliação dos aprendizados.

Palavras-chave: ciberespaço; inteligência coletiva; ensino a distância; avaliação virtual.

\section{Methodological Perspectives of Teaching in Cyberspace: The Case of Virtual Seminars in CEAD / UFOP}

\begin{abstract}
This study presents some contemporary concepts such as cyberspace and collective intelligence, which emerged from the changes undergone by information technology and communication. These changes allowed the appropriation of new spaces of interaction for the actors involved in the teaching-learning process: students, tutors and teachers. For a better understanding of concepts, this study aims to analyze a case that has two closely related facts: a survey of expectations of a discipline and as a result of this, the development of a different methodology for virtual evaluation. Finally, elaborates a discussion about the new methodology, and analyzes the processes and evaluation of the learning.
\end{abstract}

Key-words: cyberspace, collective intelligence, distance learning, virtual evaluation. 


\section{Introdução}

O avanço da tecnologia provocou uma série de mudanças significativas em termos de comunicação e interação das pessoas, resultando em novas configurações no processo de ensino e aprendizagem. A sociedade contemporânea experimenta possibilidades inimagináveis a décadas atrás. O surgimento da internet, a consolidação do uso dos computadores e a massificação do acesso a estes dois recursos possibilitam às pessoas vivenciarem novas experiências no processo de educação.

O uso dos computadores e da internet tem possibilitado a expansão da escola para além de seus limites físicos, reduzindo significativamente a dependência, no processo de aprendizado, de recursos como salas de aula, livros, bibliotecas, e até mesmo do professor. Aos alunos é possibilitado o acesso livre a vários tipos de conteúdo, tais como aulas em vídeos e até livros completos disponíveis na rede. Somase a estas possibilidades a vantagem de se acessar tais conteúdos em distintos momentos e localidades, bastando para isso um computador com acesso a internet.

Essa é a realidade que se pode verificar na sociedade atual, em especial no campo da educação no qual existem diversos cursos, inclusive nos níveis de graduação e pós-graduação. Uma extensa lista de opções de cursos e instituições utilizam-se do aparato disponibilizado pelas novas tecnologias, permitindo que professores e alunos localizados em diferentes localidades possam se encontrar no ciberespaço e exercerem seus papéis a partir deste ambiente. É fato que o ensino a distância não se apresenta como novidade, tendo passado por várias fases de desenvolvimento, tendo se baseado historicamente em um processo unidirecional e pouco dinâmico. Contudo, é na atualidade que se pode perceber que tal evolução permitiu aos atores envolvidos nos processos educacionais apropriarem-se das ferramentas tecnológicas para ampliar as possibilidades de interação, a partir de várias ferramentas úteis para mediar e sistematizar o processo.

Neste sentido, e visto os desafios e curiosidades advindos da dinâmica da educação na modalidade a distância, vários questionamentos emergem, entre os quais destacamos o que orienta este estudo: Como dinamizar os processos de ensinoaprendizagem por meio do desenvolvimento de metodologias de ensino que aproveitem as singularidades do ciberespaço?

Para responder a este questionamento este estudo objetiva analisar um caso ocorrido no curso de Administração Pública, oferecido na modalidade a distância na Universidade Federal de Ouro Preto - UFOP, onde, através de uma pesquisa de expectativa junto aos alunos, identificou-se uma necessidade de atividades que propiciassem maior interação entre os alunos, mesmo que estes estivessem separados por centenas de quilômetros. Desta forma, além da exposição sucinta da pesquisa é apresentada também a experiência didática de uma atividade avaliativa virtual realizada, indo de encontro à parte das expectativas encontradas.

Para viabilizar a análise deste caso, a próxima seção apresenta a revisão de literatura de temas como transformações tecnológicas, ciberespaço e inteligência coletiva, fundamentais para a compreensão dos fenômenos que ocorrem nos processos educacionais atuais, que se passam nos ambientes virtuais. Já na segunda seção apresenta-se o relato do caso, sendo que a primeira subseção identifica as expectativas dos alunos em relação a uma disciplina, a segunda relata o uso de uma metodologia diferenciada na busca de atendimento destas expectativas e a última que apresenta uma discussão sobre os resultados obtidos com o uso desta metodologia. Por fim, a terceira seção apresenta as considerações finais deste estudo a partir de uma listagem das 
principais conclusões, limitações e orientações de pesquisa que foram vislumbradas a partir das experiências discutidas.

\section{Transformações Tecnológicas, o Ciberespaço e a Inteligência Coletiva}

Para Castells (1999) a sociedade tem passado por uma série de transformações em virtude do desenvolvimento dos sistemas eletrônicos e das possibilidades tecnológicas ofertadas para a comunicação e interação social. Tais transformações têm impactado consideravelmente outros aspectos, como a redução das distâncias, os modos de se relacionar e a própria mudança cultural, que ele denomina "cultura internet".

Negroponte (1995) recorre a uma comparação entre a era industrial e a era da informação, argumentando que nesta última há uma semelhante preocupação com as economias de escala da primeira, porém menos preocupações com o espaço e o tempo. A partir daí, o autor afirma que "a vida digital exigirá cada vez menos que você esteja num determinado lugar em determinada ora, e a transmissão do próprio lugar vai começar a se tornar realidade" (NEGROPONTE, 1995, p. 159).

A internet impactou a humanidade, constituindo um novo espaço de interação social e econômica, denominado de ciberespaço. Para Castells (1999) não existe uma definição rígida da relação entre tempo e espaço, visto que informações e elementos de diferentes tempos existem em diversos locais de forma simultânea. É neste sentido que Hall (2005, p. 70) concede especial atenção ao ciberespaço informando que "diferentes épocas culturais têm diferentes formas de combinar essas coordenadas espaço-tempo".

Para Corrêa (2004, p.5) "o ciberespaço potencializa o surgimento de comunidades virtuais e de agregações eletrônicas em geral que estão delineadas em torno de interesses comuns, de traços de identificação", visto que neste tipo de ambiente as noções de espaço e tempo como barreiras para as relações são ignoradas, podendo aproximar pessoas que nem ao menos tenham se encontrado pessoalmente. Assim, há que se entender que este espaço se apresenta apenas como meio para as conexões e interações entre os indivíduos e não como fator de mudanças, já que, ao possibilitar a comunicação entre indivíduos de diferentes partes do planeta, possibilita o intercâmbio de idéias e conhecimento entre as pessoas.

Já na visão de Lévy (2000, p.92) ciberespaço é "o espaço de comunicação aberto pela interconexão mundial dos computadores e das memórias dos computadores". Para Lemos (2004), o ciberespaço é, antes de qualquer coisa, um ambiente virtual, no qual o lugar é criado por meio de uma rede de computadores, sejam eles interligados ou não, se apresentando como

um espaço sem dimensões, um universo de informações navegável de forma instantânea e reversível. Ele é, dessa forma, um espaço mágico, caracterizado pela ubiqüidade, pelo tempo real e pelo espaço não-físico. Estes elementos são característicos da magia como manipulação do mundo. (LEMOS, 2004, p.128)

O desenvolvimento das novas tecnologias de comunicação e informação altera sobremaneira os processos de comunicação, produção e distribuição de bens e serviços e configuram novos contextos sociais, culturais e políticos (LÉVY, 2000; LEMOS; LÉVY, 2010). Rheingold (1996, p.19) chama a atenção para a relevância assumida pela internet no contexto atual da sociedade, assumindo que o futuro dela "está ligado ao futuro da comunidade, da democracia, da educação, da ciência e da vida intelectual". 
De forma saudosista, Baudrillard (1997) chama a atenção para as mudanças que o desenvolvimento da tecnologia trouxe para o cotidiano das pessoas, argumentando que
vídeo, tela interativa, multimídia, internet, realidade virtual: a interatividade nos ameaça de toda parte. Por tudo, mistura-se o que era separado; por tudo, a distância é abolida: entre os sexos, entre os pólos opostos, entre o palco e a platéia, entre os protagonistas da ação, entre o sujeito e o objeto, entre o real e o seu duplo. (BAUDRILLARD, 1997, p. 145)

Por outro lado, Rheingold (1996) discute a importância da Comunicação Mediada por Computador (CMC) para a democratização da informação e aumento da liberdade de expressão. Ainda neste sentido, Castells (1999) argumenta que a busca de identificação e sociabilidade expuseram o surgimento de uma nova cultura ocasionada pela expansão dos ciberespaços que eclodiram a partir do desenvolvimento das Tecnologias da Informação e Comunicação (TICs) e da CMC, e que dão base para as formas de relações e as atividades das pessoas.

Neste sentido, estabeleceu-se um novo conceito de cultura, cunhado por Castells (1999) como "Cultura Internet", que se apóia na realidade social, construída no espaço das redes. Estes espaços são definidos como espaço de fluxos, nos quais as práticas sociais da sociedade se disseminam e são organizadas materialmente. O que pode ser claramente observado nos processos relacionados à educação nos ambientes virtuais.

De qualquer forma, "a interatividade, seja ela analógica ou digital, é baseada numa ordem mental, simbólica e imaginária, que estrutura a própria relação do homem com o mundo" (LEMOS, 2004, p.115). Assim, pode-se compreender como a interatividade virtual possibilita a aproximação dos atores na dinâmica da educação.

Para Castells (1999), a comunicação entre os membros de uma rede de usuários exerce papel primordial para a manutenção e crescimento destas, sendo que sua possibilidade de crescimento ilimitado se sustenta com base nas condições de interação e trocas de informações. Além disso, compreende-se que a dinâmica surgida neste tipo de interação é que permite se pensar a apropriação do ciberespaço para desenvolver processos relacionados ao ensino e ao aprendizado.

Na concepção de Lemos e Lévy (2010, p.14), a cibercultura se apóia em três tendências: a interconexão, a criação de comunidades e a inteligência coletiva. Por interconexão, entende-se o estabelecimento de relações entre computadores, meios de comunicação, pessoas, grupos e instituições. Já a criação de comunidades virtuais antecede a própria internet, sendo uma forma dos indivíduos explorarem outras possibilidades de comunicação e relações. Por fim, a inteligência coletiva "representa o apetite para o aumento das capacidades cognitivas das pessoas e dos grupos, quer seja a memória, a percepção, as possibilidades de raciocínio, a aprendizagem ou a criação".

Lemos e Lévy (2010) assinalam a importância dos processos relacionados à Inteligência Coletiva no ambiente virtual. Este tipo de inteligência pode ser considerado como uma das bases para o desenvolvimento da cibercultura diante dos novos comportamentos assumidos nestes espaços e tende a crescer diante do aumento das possibilidades comunicacionais e de liberdade individual e coletiva, visto que a produção, distribuição e consumo de informações não se enquadram na denominação de "mídias de massa" (LÉVY, 2002; LEMOS; LÉVY, 2010).

Lemos e Lévy (2010, p.221) discutem o conceito de Inteligência Coletiva, o considerando um pleonasmo, visto que a inteligência já é por si só coletiva. Contudo, ela é utilizada para melhor qualificar a potência de autocriação dos grupos sociais. Além disso, de acordo com Lévy (2000, p.30), os "processos de inteligência coletiva V. $10 \mathrm{~N}^{\mathrm{o}} 1$, julho, 2012 
desenvolvem-se de forma eficaz graças ao ciberespaço", este que possibilita "acelerar cada vez mais o ritmo da alteração tecno-social, o que torna ainda mais necessária a participação ativa na cibercultura". De forma semelhante, Rheingold (1996) discute estas possibilidades por meio do ciberespaço, mas denomina este processo de "mentes coletivas".

Entendida a influência exercida pelo estabelecimento do ciberespaço, na próxima seção busca-se esclarecer as possibilidades metodológicas de ensino por meio da apresentação de um caso do Centro de Educação Aberta e a Distância (CEAD) da Universidade Federal de Ouro Preto (UFOP).

\section{Apresentação do Caso}

O Centro de Educação Aberta e a Distância (CEAD) da Universidade Federal de Ouro Preto (UFOP) se constitui numa unidade acadêmica com enfoque em cursos na modalidade a distância nos níveis de graduação e pós-graduação. Tal unidade foi estabelecida a partir de aprovação pelo Conselho Universitário da instituição em dezembro de 2003. Entre os cursos de graduação, destaca-se o de Administração Pública, o qual é foco do desenvolvimento deste caso.

Neste curso, a elaboração do conteúdo das disciplinas e as formas de avaliação deste conteúdo não seguem regras rígidas. As resoluções do curso apenas orientam quanto à distribuição dos pontos entre as avaliações, as formas de avaliações que podem ser utilizadas, dentre outros aspectos mais abrangentes. Em virtude disso, os professores dos vários cursos da unidade, em especial o de Administração Pública, utilizam de avaliações finais eminentemente presenciais, sejam elas no formato de 'provas' tradicionais com questões dissertativas e de múltipla escolha, ou mesmo por meio de seminários finais. Contudo, as demais atividades desenvolvidas durante o curso são realizadas no ambiente virtual através do $M_{o o d l e}{ }^{1}$, tais como fóruns, questionários, wikis, chats e atividades individuais com base no envio de arquivos contendo resenhas, textos críticos, entre outros.

\subsection{Realidade Observada}

Os autores deste estudo perceberam através de mensagens postadas no fórum "Fale com o Professor", bem como em discussões durante as videoconferências ${ }^{2}$, que os alunos do curso de Administração Pública criticavam, com frequência, a restrita variedade de metodologias que os permitem interagir com os colegas, tutores e professores, requerendo maior variedade deste tipo de atividade coletiva.

Estes posicionamentos puderam ser identificados de forma clara e precisa numa pesquisa de expectativa aplicada no início da disciplina "EAD320 - Finanças Públicas e Programação Orçamentária" ao $6^{\circ}$ período do curso. A pesquisa foi realizada em seis pólos com o total de 192 alunos, porém contou com 131 respondentes. O questionário tomado por base para a realização da pesquisa é a ferramenta denominada de "COLLES (expectativas), disponibilizado nas ferramentas do Moodle.

As questões levaram em consideração as expectativas dos alunos, em relação às suas experiências anteriores em demais disciplinas ofertadas, como forma de buscar aprimoramentos no decorrer da disciplina em questão.

Para compreender a expectativa da turma de alunos, foram utilizados questionamentos que levaram em consideração cinco variáveis, a saber: Relevância da disciplina para a formação, Reflexão Crítica quanto à participação e aprendizado já 
obtidos no curso, Interatividade nas disciplinas ofertadas anteriormente, Apoio dos Tutores no decorrer do curso, Apoio dos Colegas no desenvolvimento das atividades acadêmicas e Compreensão dos conteúdos. Para cada uma das variáveis foram formuladas quatro perguntas e o resultado geral da pesquisa pode ser visto, esquematicamente, na Figura 1.

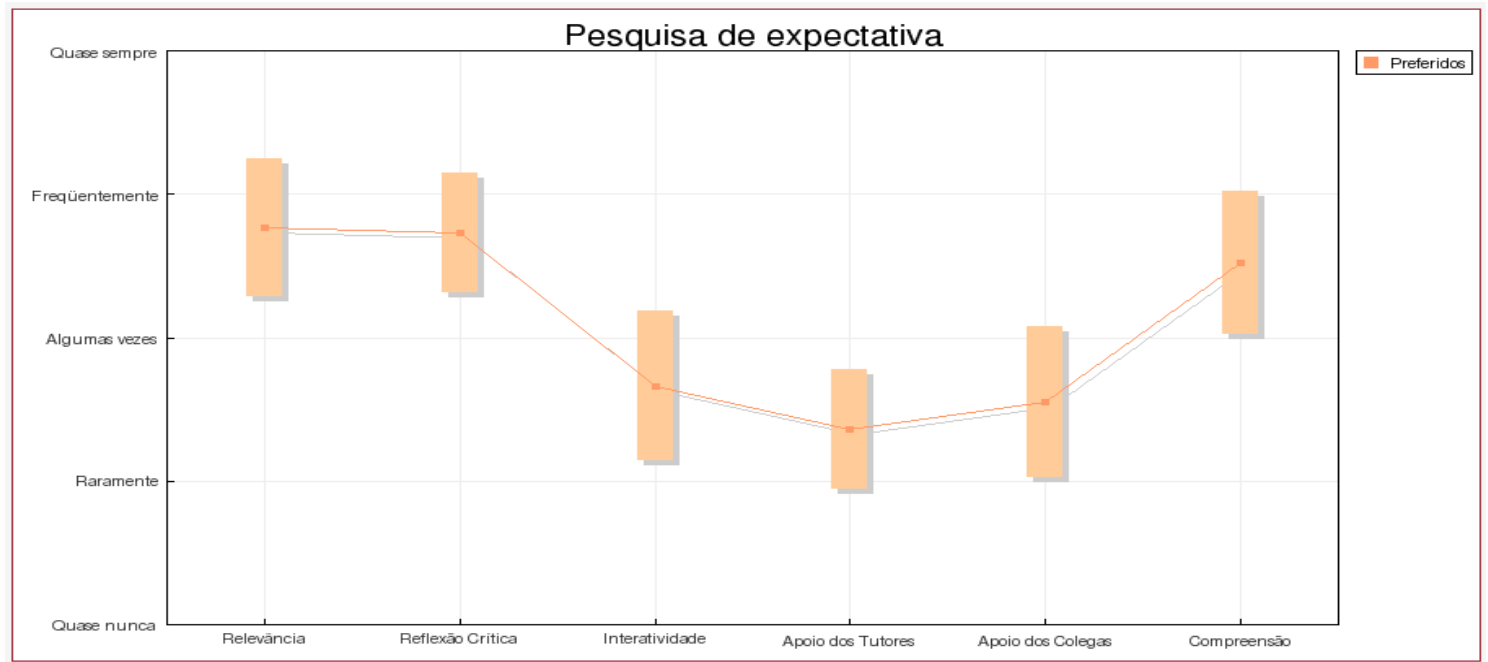

Figura 1: Resultados da Pesquisa de Expectativa

Fonte: Baseado em dados da pesquisa de expectativa da disciplina oferecida no ambiente virtual

Para os alunos respondentes, questões como a Relevância da disciplina para suas formações e a Reflexão Crítica quanto ao comportamento dos alunos foram assinaladas como frequentes, isto é, consideram atendidas suas expectativas em relação aos conteúdos e à forma como eles se dispõem nas disciplinas e curso. Além disso, a Compreensão em relação aos conteúdos foi considerada como frequente, entendendo-se que os conteúdos não apresentam maiores dificuldades.

Por outro lado, o Apoio dos tutores e colegas não ocorre constantemente, sendo definido como algo esporádico. A partir daí pode-se inferir que a restrita Interatividade seja resultado, em parte, desta percepção dos alunos quanto ao apoio recebido no desenvolvimento de suas atividades acadêmicas.

Os resultados obtidos nesta pesquisa motivaram à utilização de uma alternativa metodológica apresentada na próxima subseção através da experiência que visou adequar a atividade final de avaliação englobando alunos, tutores e professor para satisfazer as expectativas dos alunos quanto à interatividade e apoio dos tutores e colegas.

\subsection{Mudanças Implementadas}

Dentre as críticas, destacavam-se as direcionadas às avaliações finais das disciplinas que são aplicadas presencialmente. A proposta é que fossem desenvolvidas no ambiente virtual, da mesma forma como as atividades são desenvolvidas no decorrer das disciplinas. Assim, propôs-se a realização de um seminário virtual com o tema " $\mathrm{O}$ processo orçamentário como instrumento de construção da cidadania nos municípios", como instrumento final de avaliação virtual da disciplina.

A ideia inicial do seminário foi a de que os alunos se reunissem em grupos de no máximo cinco alunos, com a finalidade de pesquisar a realidade orçamentária no 
município onde o pólo está localizado ou em outro escolhido por eles. Nesta direção, os alunos foram orientados a buscar o apoio dos tutores e dos colegas e construir um trabalho coletivo. Estas orientações foram dadas como forma de responder positivamente às demandas dos alunos, a partir da compreensão que se teve das expectativas através da pesquisa anterior.

O objetivo do seminário foi que os alunos compreendessem na prática como se processa o ciclo do orçamento. E se o orçamento no município era elaborado e executado de forma participativa e cidadã. Para a apresentação, estabeleceu-se que seria realizada uma videoconferência com os seis pólos nos quais a disciplina estava sendo ofertada simultaneamente, sendo os pólos localizados nos municípios de: Bálsamo, Ipatinga e Lagamar, localizados no estado de Minas Gerais, e; Itapevi, Jandira e São José dos Campos, localizados no estado de São Paulo.

Inicialmente, estabeleceu-se que, caso os alunos não constituíssem os grupos no período determinado pelo professor, os tutores deveriam dividir as turmas. Em sua maioria, os alunos não se agruparam e nem foram agrupados pelos tutores. Depois de pelo menos três orientações gerais via mensagem para alunos e tutores, os grupos foram constituídos com pelo menos 20 dias de atraso.

Durante a etapa de formação dos grupos surgiu uma nova discussão: data de apresentação do seminário. Isto por que os alunos se dirigem ao pólo apenas num final de semana para realização das avaliações finais e a metodologia estabelecida para o seminário dependeria do deslocamento dos mesmos em dois finais de semana. $\mathrm{O}$ estabelecimento da nova data foi feita por votação, mas muitos alunos não concordavam com esta forma democrática de decisão, solicitando que o seminário ocorresse na mesma data das avaliações presenciais das demais disciplinas.

Vencidas as fases de formação dos grupos e estabelecimento da data de apresentação do seminário, iniciou-se a fase de pesquisa de campo e confecção dos pôsteres. Os alunos saíram a campo e em alguns casos se surpreenderam com a realidade orçamentária dos municípios pesquisados, quer pelo volume de recursos arrecadados e aplicados, quer pelo reduzido montante e inúmeras demandas encontradas.

A partir da pesquisa de campo e da confecção dos trabalhos, estes foram apresentados em formato de pôster, sendo transmitido para os demais pólos, através de videoconferência. A apresentação do seminário ocorreu num sábado pela manhã, dia no qual os alunos apresentam maior disponibilidade. Anteriormente às apresentações, foi necessário organizar a ordem pela qual os grupos se expressariam. Para isso foi realizado um sorteio, no qual todos os pólos puderam acompanhar e atestar a transparência desta atividade.

É importante destacar que este tipo de atividade demanda uma estrutura física que comporte as atividades virtuais, a fim de que a interação seja propícia para os fins aos quais se destina. Contudo, há algumas restrições em termos desta estrutura nos diferentes pólos, já que se inserem em distintas realidades com várias diferenças em termos de tecnologia e estrutura física disponibilizada para as atividades acadêmicas. Quando vencidas as dificuldades de conexão de rede com os pólos, deu-se início às apresentações. Contudo, o pólo de Lagamar/SP apresentou problemas durante a realização da atividade, visto que no decorrer das apresentações parte da capacidade de transmissão foi perdida, levando os participantes deste pólo a participarem apenas por meio do som, enquanto os demais pólos continuaram com som e imagem na transmissão. 
Mesmo em decorrência das dificuldades apontadas, foi possível apropriar-se mais uma vez do ambiente proporcionado pelo ciberespaço, levando a discussões que possibilitaram a construção do conhecimento pela coletividade, aliando-se tanto os grupos de um mesmo pólo, como também de pólos diferentes.

$\mathrm{Na}$ próxima seção são apresentadas as principais discussões acerca da metodologia utilizada para a avaliação virtual final, de acordo com nossas percepções.

\subsection{Discussões}

A interação por meio do ciberespaço mostrou-se benéfica em virtude das diferentes realidades demonstradas no seminário virtual, tendo aberto espaço para o conhecimento de distintas experiências, discussões e considerações. Por fim, na análise dos atores envolvidos a repercussão dos resultados foi de que o ciberespaço tem mais opções a oferecer que as já conhecidas.

Outra observação relevante é que, apesar de os alunos reclamarem da pouca utilização de metodologias que possibilitem a interação com colegas e tutores, quando estas metodologias são oferecidas, boa parte resiste e não adere às novas propostas, já que estas necessitam de uma adequação na rotina para possibilitar encontros $\mathrm{e}$ discussões com os colegas e tutores em mais uma atividade.

De modo geral, o que se constatou foram trabalhos de ótima qualidade e a interação entre alunos de um mesmo período e diferentes cidades. Entretanto, a qualidade de apresentação dos pôsteres por videoconferência ficou comprometida. Melhor seria se os dados tivessem sido apresentados por outro meio como, por exemplo, por slides disponibilizados em cada um dos polos, para facilitar a visualização dos participantes. A partir destas observações, buscou-se inserir na disciplina, e em outras lecionadas pelos autores, métodos como este que possibilitam aumentar a interação entre alunos e tutores, apropriando-se de um espaço que guarda, ao mesmo tempo grandes desafios e oportunidades de aprendizado.

\section{Considerações Finais}

Este trabalho buscou identificar novas possibilidades de apropriação do ciberespaço no sentido de utilizar-se do ambiente para maior interação e construção de conhecimentos por meio da apresentação e discussão de relatos vivenciados nos trabalhos de campo. Os trabalhos foram realizados por alunos de diferentes pólos do ensino a distância do curso de Administração Pública do CEAD/UFOP, que possibilitou compreender a dinâmica da criação coletiva, por muitos denominada de inteligência coletiva ou mentes coletivas que, a nosso ver, guarda estreitas ligações com as possibilidades ofertadas na virtualidade do ciberespaço.

Este estudo colabora, em termos teóricos, para reconhecimento da aplicação dos conceitos de ciberespaço e inteligência coletiva no desenvolvimento de metodologias para o ensino de cursos a distância. Em termos práticos, demonstra as possibilidades de desenvolvimento de ferramentais metodológicos úteis para ampliar a interação entre alunos, tutores e professores, bem como avaliar o conhecimento adquirido no processo virtual de aprendizagem.

Contudo, para realização deste trabalho deparou-se com algumas limitações, entre elas as referentes ao questionário padrão disponível na plataforma Moodle, que não permite incorporar outras questões. Além disso, a disciplina é ofertada aos alunos num espaço de tempo que dificulta reconhecer as expectativas via pesquisa e saná-las a

V. $10 \mathrm{~N}^{\mathrm{o}} 1$, julho, 2012 
tempo, se houver contratempos como os narrados no caso, em relação aos atrasos na formação de grupos e definição de datas.

Os dados e discussão apresentados permitem formular orientações para futuras pesquisas empíricas, entre as quais destacamos a elaboração de outra ferramenta (questionário) para mensurar expectativas, mais completo que aquele disponibilizado pelo Moodle. De posse desta ferramenta atualizada, poder-se-ia realizar um estudo comparativo, entre disciplinas que utilizassem o seminário como avaliação final e outras que não o utilizasse, aplicando o questionário de expectativas e de outro questionário ao final da disciplina, viabilizando comparação entre a expectativa e o quanto dela foi atendida, com e sem o uso do seminário.

\section{NOTAS}

\footnotetext{
${ }^{1}$ Consiste numa interação entre duas ou mais pessoas distantes fisicamente, em tempo real, a qual, por meio de tecnologias, permite a cada um dos participantes comunicar-se com os demais como se estivessem reunidos num mesmo local.

${ }^{2}$ Consiste numa interação entre duas ou mais pessoas distantes fisicamente, em tempo real, a qual, por meio de tecnologias, permite a cada um dos participantes comunicar-se com os demais como se estivessem reunidos num mesmo local.
}

\section{Referências Bibliográficas}

BAUDRILLARD, J. Tela total: mito-ironias da era do virtual e da imagem. Trad. Juremir Machado da Silva. Porto Alegre: Sulina, 1997.

CASTELLS, Manuel. A sociedade em rede. São Paulo: Paz e Terra, 1999.

CORRÊA, C. H. W. Comunidades Virtuais gerando identidades na sociedade em rede. Ciberlegenda. Programa de Pós-Graduação em Comunicação da Universidade Federal Fluminense. Niterói, n.13, 2004. Disponível em: <http://www.uff.br/ciberlegenda/ojs/index.php/revista/article/view/226/122> Acesso em: 23 jan. 2012.

HALL, S. A identidade cultural na pós-modernidade. Trad. Tomaz Tadeu da Silva, Guaracira Lopes Touro. 10. ed. Rio de Janeiro: DP\&A, 2005.

LEMOS, A. Cibercultura: tecnologia e vida social na cultura contemporânea. 2.ed. Porto Alegre: Sulina, 2004. 295p.

LEMOS, A.; LÉVY, P. O Futuro da internet: em direção a uma ciberdemocracia planetária. São Paulo: Editora Paulus, 2010. 258p.

LÉVY, P. Cibercultura. Trad. Carlos Irineu da Costa. 2.ed. São Paulo: Editora 34, 2000. 260p.

LÉVY, P. Ciberdemocracia. Trad. Alexandre Emílio. Lisboa: Instituto Piaget, 2002. 249p.

NEGROPONTE, N. Vida digital. Trad. Sérgio Tellaroli. 2.ed. São Paulo: Companhia das Letras, 1995.

RHEINGOLD, H. Comunidade virtual. Trad. Helder Aranha. Lisboa: Gradiva, 1996. 